\title{
Review Article on Prevention and Management of Hypotension in Obstetrics after Spinal Anesthesia Developing country
}

\author{
Demeke Yilkal* \\ Department of Anesthesia, University of Gondar, Ethiopia
}

Submission: July 14, 2018; Published: January 24, 2019

*Corresponding author: Demeke Yilkal, Department of Anesthesia, University of Gondar, College of medicine and Health science, Ethiopia

\begin{abstract}
Objective: This study was conducted to develop evidence-based clinical practice guidelines for prevention and management of hypotension in obstetrics after spinal anesthesia. Hypotension in obstetric surgery after spinal anesthesia is the common complication we encounter. Prevention and adequate treatment of post spinal hypotension is a major concern of obstetric anesthetist. This guide line will give an insight how to prevent and manage post spinal hypotension.
\end{abstract}

Options: The following interventions were systematically reviewed for inclusion in the guidelines. Pre-loading vs co-loading), early versus late EN, $12 \mathrm{~cm}$ pelvic wedge vs. $12 \mathrm{~cm}$ lumbar wedge, crystalloid, colloid and ephedrine with three different combinations, Manual displacer vs. $15^{\circ}$ left lateral tilt, $20^{\circ}$ left lateral tilt vs. horizontal position, $10^{\circ}$ head dawn tilt vs. horizontal position, slow vs fast speed of injection.

Evidence: We systematically searched hinari/PubMed/PMC, Google scholar, the Cochrane Library for randomized controlled trials and meta-analyses of randomized controlled trials that evaluated post spinal anesthesia hypotension in obstetrics. We also searched reference lists and personal files, considering all articles published or unpublished available by December 2017. Each included study was critically appraised.

Summary of evidence and recommendation: When considering post spinal hypotension in obstetrics, we strongly recommend that coloading has equal importance like that of preloading by avoiding unnecessary time wastage. We recommend that no single method for treatment and prevention of hypotension secondary to spinal anesthesia is developed.

Keywords: Spinal anesthesia; Obstetric surgery; Preloading; Co loading; Positioning; Hypotension; Spinal Anesthesia; Preloading; Coloading; Fentanyl; Vasopressors; Obstetrics

\section{Objectives of Guideline Development}

a) The goal of this guideline is just to improve the value of health care by recommending treatment with favorable benefit /harm ratio.

b) To address explicitly strength of evidence interims of external validity (generalizability), internal validity and patient-oriented outcome.

c) To have a common consensus in some agreed situations.

d) To manage this challenging and frequent problems by using available things.

\section{Introduction}

Cesarean section is among the most commonly performed surgeries in women and neuro axial anesthesia is the technique of choice for this procedural though numerous side effects related to obstetric anesthesia had been described, subarachnoid anesthesia has a clear tendency to be used more often than epidural and combined spinal-epidural technique [1]. It is safe, easy to perform, effective, low failure rate, a few systemic local anesthetic toxicities, inexpensive, prevents aspiration pneumonia, and has a high rate of maternal satisfaction Produces a deep anesthesia, inhibits the stress response to surgery, blunts the autonomic and somatic responses to pain, and facilitate breathing, coughing, sighing and early ambulation.

Finally, efferent sympathetic blockade results in increased blood flow to the blocked area resulting in better wound healing. It also reduces the risk of deep vein thrombosis and thromboembolism. Pregnancy produces significant hemodynamic changes allowing the cardiovascular system to meet the increased metabolic demands of pregnancy. The increase in blood volume enables increased uterine blood flow to meet growing nutritional and oxygenation needs of the fetus. It also enables blood loss of average $500 \mathrm{ml}$ at vaginal delivery and $1000 \mathrm{ml}$ at cesarean delivery, without physiological decompensation. Maternal hypotension 
after spinal anesthesia for cesarean delivery, without prophylactic measures, has a very high incidence (80\%-100\%) yes!!!!

\section{Controversial ideas in managing hypotension}

a) Preloading or coloading for hypotension prevention.

b) Left lateral tilt or supine position.

c) Vasopressor choice in hypotension treatment in obstetrics.

I try to find some researches to support the evidence-based guideline and for best practice. Research findings from HINARI for the above guideline are listed here according to their level of evidence, and internal validity and I try to summaries after appropriate appraisal of the research findings

\section{Preload or co-load for spinal anesthesia for elective cesarean delivery}

A meta-analysis showed that studies comprised of 518 patients. The incidence of hypotension in the coload group was $159 / 268$ (59.3\%) compared with 156/250 (62.4\%) in the preload group (odds ratio $[\mathrm{OR}]=0.93 ; 95 \%$ Confidence Interval $[\mathrm{CI}]$ 0.541.6) [2]. There were no significant differences between groups in any of the other outcomes and concluded that it is unnecessary to delay surgery in order to deliver a preload of fluid.

\section{Prevention of post-spinal hypotension using crystalloid, colloid and ephedrine with three different combinations: A double blind randomized study}

\section{Advanced biomedical research}

The benefit of prophylactic combination therapy using crystalloid and colloid preload with ephedrine has not cleared to prevent maternal hypotension after spinal anesthesia at cesarean delivery. This study evaluated the efficacy of three combinational methods to prevent hypotension following spinal anesthesia. In this prospective double blind trial, 150 candidates of elective cesarean delivery under spinal anesthesia were randomly allocated to three treatment groups; 1---Ringer's Lactate (RL) solution $(15 \mathrm{ml} / \mathrm{kg})$ plus Hemaxel $(7 \mathrm{ml} / \mathrm{kg})$ preload, 2---RL solution $(15 \mathrm{ml} / \mathrm{kg})$ preload plus ephedrine (15mg, IV, bolus), $3---H e m a x e l(7 \mathrm{ml} / \mathrm{kg})$ preload plus ephedrine $(15 \mathrm{mg}$, IV, bolus). Maternal hemodynamic changes every 5 minute for $60 \mathrm{~min}$ after spinal injection, nausea/vomiting, and neonatal condition were compared among the groups.



Figure 1: Guidelines for preventing and managing hypotension during spinal anesthesia for cesarean delivery.

This study concluded that the use of crystalloid $15 \mathrm{ml} / \mathrm{kg}$ plus ephedrine 15IV bolus as a prophylactic is best to prevent hypotension comparing to the others [3]. Small dose of spinal anesthesia as a combined spinal epidural anesthesia. To provide effective anesthesia. Van de Velde $\mathrm{M}$ et al. reported a significant reduction in blood pressure rate using $6.5 \mathrm{mg}$ hyperbaric bupivacaine as compared with $9.5 \mathrm{mg}$ bupivacaine. In both groups $25 \mu \mathrm{g}$ fentanyl was added. Langesæter et al. recently showed that decreasing the spinal dose bupivacaine from $10 \mathrm{mg}$ to $7 \mathrm{mg}$, significantly improves hemodynamic stability, when used with a 
low-dose ephedrine continuous infusion of $2.5 \mathrm{mg} / \mathrm{min}$. Epidural supplementation $10 \mathrm{ml}$ of bupivacaine can be used for patients who do not achieve an adequate block for surgery (Figure 1).

\section{Adjuvants used for spinal anesthesia}

Addition of intrathecal opioids to local anesthetics seems to improve the quality of block and prolong the duration of analgesia and decrease unwanted side effect like hypotension. A study in western galilee hospital in Israel showed the following

In this follow up study 32 patients were scheduled for c/s. Patients were group in two

a) Group one patients taking $10 \mathrm{mg}$ isobaric bupivacaine.

b) Group two patients taking $5 \mathrm{mg}$ isobaric bupivacaine and $25 \mathrm{mcg}$ fentanyl.

In this study if BP drops more than $20 \%$ of base line $5 \mathrm{mg}$ IV ephedrine given

a) Result- peak sensory level was T3 vs. T4.5.

b) Motor blockage were more intense in group one.

c) Hypotension Treatment 94\%vs 31\%.

d) Persistent hypotension $4.8 \%$ vs. $0.6 \%$.

e) Ephedrine consumed - 23.8mg vs. $2.8 \mathrm{mg}$.

\section{Conclusion}

$5 \mathrm{mg}$ isobaric bupivacaine with $25 \mathrm{mcg}$ fentanyl provide spinal anesthesia with less hypotension.

\section{Positioning}

Maternal position during $\mathrm{c} / \mathrm{s}$ for preventing maternal and neonatal complications (review).

\section{The Cochrane Collaboration}

Randomized trial of women undergoing c/s comparing different positions. They identified 17 studies total of 683 women included. At the end of analysis, they found that $12 \mathrm{~cm}$ pelvic wedge vs. $12 \mathrm{~cm}$ lumbar wedge [4]. There were fewer hypotensive events when using $12 \mathrm{~cm}$ lumbar wedge compared to $12 \mathrm{~cm}$ pelvic wedge. Manual displacer vs. $15^{\circ}$ left lateral tilt. The incidence of hypotensive events was lower in the manual displacer group (two events vs. 18 events). $20^{\circ}$ left lateral tilt vs. horizontal position. There was no change in systolic and diastolic BP. $10^{\circ}$ head dawn tilt vs. horizontal position. No difference in the incidence of hypotension in systolic Bp but there was statically significant difference in diastolic BP lower in head dawn tilt group.

\section{Speed of injection}

A prospective observational study showed the inference of speed of injection on maternal hypotension.

a) In this study 50 elective $\mathrm{C} / \mathrm{S}$ women groped in to two group. b) Group one-took $2 \mathrm{ml}$ of hyperbaric bupivacaine $+2 \mathrm{mcg}$ sufentanyl.

c) Group two-took $2 \mathrm{ml}$ hyperbaric bupivacaine plus $2 \mathrm{mcg}$ sufenatanyl.

d) Hypotension (SBP less tan 100mmhg was promptly treated with $5 \mathrm{mg}$ IV ephedrine in both groups).

\section{Result}

Slow injection significantly reduces the incidence of hypotension (65\% in 120 s and $92 \%$ in others p value 0.03 ). In addition, onset of hypotension was delayed has shorter duration and required less ephedrine $11 \mathrm{mg}$ vs. $19 \mathrm{mg} \mathrm{p}=0.019$, Anesthesia was satisfactory for all women. Conclusion $-2 \mathrm{ml} / \mathrm{min}$ injection rate may be simply and effective way to reduce the incidence and severity of hypotension during $\mathrm{c} / \mathrm{s}$ under spinal anesthesia Conclusions drawn from the research review. From the above research findings, I can conclude the following key points.

i. Avoidance of unnecessary delay for preloading of patient with crystalloid fluids since coloading has good effect to prevent hypotension.

ii. If possible, use the combination of crystalloids and vasopressors for prophylaxis and treatment of hypotension secondary to spinal anesthesia.

iii. Use available drugs in our set for good, prolonged analgesia and to minimize side effect of local anesthesia especially fentanyl.

iv. Lateral position does not have significant effect on BP.

v. No single method for treatment and prevention of hypotension secondary to spinal anesthesia.

vi. Head dawn position has no place in treating hypotension.

vii. NB -There is no single method that prevents spinal induced hypotension Use combination of therapies. Check maternal blood pressure every 2-5 minutes after the spinal is placed.

viii. This guide line may not work in extreme situations like extremely malnourished, extremely short and parturient other concomitant systemic disease.

ix. The stars show level of evidence *level one, **level two, ***level three evidence.

x. In a bleeding patient consider transfusion.

\section{References}

1. Kuczkopwski KM, Reisner LS, Lin D (2009) Anesthesia for cesarean section. In: Chestnut DH, Polley LS, Tsen LC, Wong CA (Eds.), Chestnut's Obstetric Anesthesia: Principles and Practice. (4 $4^{\text {th }}$ Edn), Mosby, Philadelphia, USA, pp. 422-4255.

2. Klohr S, Roth R, Hofmann T, Rossaint R, Heesen M (2010) Definitions of hypotension after spinal Anaesthesia for caesarean section: Literature search and application to parturients. Acta Anaesthesiol Scand 54(8): 909-921. 
3. Rout C, Rocke DA (1999) Spinal hypotension associated with Cesarean section: will preload ever work? Anesthesiology 91: 1565-1567.

This work is licensed under Creative Commons Attribution 4.0 License

DOI: 10.19080/JAICM.2019.08.555735
4. Jackson R, Reid JA, Thorburn J (1995) Volume preloading is not essential to prevent spinal-induced hypotension at Caesarean section. Br J Anaesth 75(3): 262-265.

Your next submission with Juniper Publishers will reach you the below assets

- Quality Editorial service

- Swift Peer Review

- Reprints availability

- E-prints Service

- Manuscript Podcast for convenient understanding

- Global attainment for your research

- Manuscript accessibility in different formats ( Pdf, E-pub, Full Text, Audio)

- Unceasing customer service

\section{Track the below URL for one-step submission}

https://juniperpublishers.com/online-submission.php 